\title{
Experimental mode shape determination of a cantilevered hydrofoil under different flow conditions
}

\begin{tabular}{|r|l|}
\hline Journal: & Part C: Journal of Mechanical Engineering Science \\
\hline Manuscript ID & JMES-15-0234.R2 \\
\hline Manuscript Type: & Original article \\
\hline Date Submitted by the Author: & n/a \\
\hline Kemplete List of Authors: & $\begin{array}{l}\text { De La Torre, Oscar; Universitat Politècnica de Catalunya, } \\
\text { Escaler, Xavier; Universitat Politècnica de Catalunya, } \\
\text { Egusquiza, Eduard; Universitat Politècnica de Catalunya, } \\
\text { Farhat, Mohamed; École Polytechnique Fédérale de Lausanne, }\end{array}$ \\
\hline Abstract: & $\begin{array}{l}\text { Vibration and Acoustics, Piezomaterials, Multi-phase Flow, Modal Analysis, } \\
\text { Hydrodynamics, Fluid Engineering, Experimental Mechanics, Dynamic } \\
\text { Systems, Actuators }\end{array}$ \\
\hline & $\begin{array}{l}\text { The first three mode shapes of a cantilevered NACA0009 hydrofoil were } \\
\text { experimentally investigated in air and under different flow conditions in a } \\
\text { cavitation tunnel. First and second bending modes and first torsion mode } \\
\text { were determined in resonance conditions with the hydrofoil vibrating in air, } \\
\text { in still water, in flowing water or with leading edge sheet cavitation. The } \\
\text { hydrofoil was excited with embedded piezo electric ceramic (PZT) patches, } \\
\text { and the response was measured along the surface at selected positions by } \\
\text { means of a Laser Doppler Vibrometer. The modes of vibration obtained } \\
\text { from a cross correlation analysis of the signals were compared for the } \\
\text { different conditions, and the most significant differences were identified. In } \\
\text { particular, it was found that the mode shape deformation and the location } \\
\text { of the nodal lines are dependent on the fluid conditions. }\end{array}$ \\
\hline
\end{tabular}




\title{
Experimental mode shape determination of a
}

\section{cantilevered hydrofoil under different flow conditions}

\author{
O. De La Torre ${ }^{a}$ X. Escaler ${ }^{a}$, E. Egusquiza ${ }^{a}$, M. Farhat ${ }^{b}$ \\ ${ }^{a}$ Center for Industrial Diagnostics, Universitat Politècnica de Catalunya, Av. Diagonal 647, 08028 \\ Barcelona, Spain \\ b Laboratory for Hydraulic Machines, École Polytechnique Fédérale de Lausanne (EPFL), Lausanne, \\ Switzerland \\ *Corresponding author. Tel: +34 9340125 99; fax: +34 9340158 12; e-mail: escaler@mf.upc.edu
}

\begin{abstract}
The first three mode shapes of a cantilevered NACA0009 hydrofoil were experimentally investigated in air and under different flow conditions in a cavitation tunnel. First and second bending modes and first torsion mode were determined in resonance conditions with the hydrofoil vibrating in air, in still water, in flowing water or with leading edge sheet cavitation. The hydrofoil was excited with embedded piezo electric ceramic (PZT) patches, and the response was measured along the surface at selected positions by means of a Laser Doppler Vibrometer. The modes of vibration obtained from a cross correlation analysis of the signals were compared for the different conditions, and the most significant differences were identified. In particular, it was found that the mode shape deformation and the location of the nodal lines are dependent on the fluid conditions.
\end{abstract}

\section{Keywords}

Mode shapes, natural frequencies, experimental modal analysis, nodal line. 


\section{Introduction}

The study of the response and dynamic properties of structures submerged in dense fluids has been a recurring topic of research for many years (Blake 1972, Blake and Maga 1973 and Blake and Maga 1975). One of the main gaps when added mass effects are determined by comparison of a body's natural frequencies in different fluids (e.g., air-water) is related to the hypothesis that the mode shapes do not differ significantly. In this way, it is assumed that a "wet” mode shape has only shifted its frequency with respect to the equivalent "dry" one. The mode of vibration itself is considered to stay unaltered. Despite few experimental examples, e.g., Lindholm et al. (1965) and Sader (1998) wherein different nodal lines (NLs) of cantilever rectangular beams moved slightly, the mode shapes of "wet" complex structures are still accepted to be the same as the "dry” ones (Blake and Maga 1973, Rodriguez et al. 2006,). This assumption is important because it is known that even a small change in the mode of vibration can produce an important effect in terms of added mass and natural frequency shift as concluded in De La Torre et al. (2013). In this work, the authors stated that the frequency shift in submerged bodies is linearly dependent on the mass of fluid entrained by the body's deflection. Moreover, if we also have cavitating flows, where significant density variations can occur within the fluid domain, the importance of these mode shape variations may be even greater. Additionally, in structural systems with small relative gaps, such as Kaplan turbine blades, the influence of the gap on the added mass as indicated by De La Torre et al. (2014) could be enhanced by variations in the mode shape that affect the gap's dimensions.

All the literature found about this topic -which is very little- refers to the case of submerged structures in still fluid (Kwak and Yang, 2013). There is no published evidence for the case of flow conditions and even less for the case of a body submerged in a two-phase flow. Only very recently, Rajaomazava III et al. (2013) have analytically studied the structure dynamics in inhomogeneous flows, but unfortunately no experimental data has been provided. Under these conditions, the behavior of the mode shapes should also be considered because common hydraulic systems, e.g., hydro pumps, turbines, and offshore structures, are frequently subjected to them.

Therefore, the objective of this work is to experimentally determine and visualize several mode shapes of a NACA0009 hydrofoil under different fluid-structure conditions. Then, they will be analyzed and compared by visualizing the body's displacement among the tested conditions to verify their level of similarity or to quantify their differences. A cantilever NACA0009 hydrofoil, which is typically used in 
many hydro applications, has been selected because its dynamic behavior is well known by the authors thanks to previous investigations.

\section{Methodology}

\subsection{Experimental Set-up}

The whole series of tests was carried out at the High Speed Cavitation Tunnel of the École Polytechnique Fédérale of Lausanne. The characteristics and details of the cavitation tunnel were described by Avellan et al. (1987). An aluminum NACA0009 hydrofoil was chosen with a truncated trailing edge (TE) and a subsequent $45^{\circ}$ cut as shown in Figure 1 (right). The dimensions of the profile are a $100 \mathrm{~mm}$ chord and a $150 \mathrm{~mm}$ span. The material has a theoretical density of $2700 \mathrm{~kg} / \mathrm{m}^{3}$, a Young's modulus of $69 \mathrm{GPa}$ and a Poisson's ratio of 0.3 . The hydrofoil was clamped to a subjection system and installed within the cavitation tunnel test section as shown in left of Figure 1 and Figure 3 resulting in a cantilever configuration.

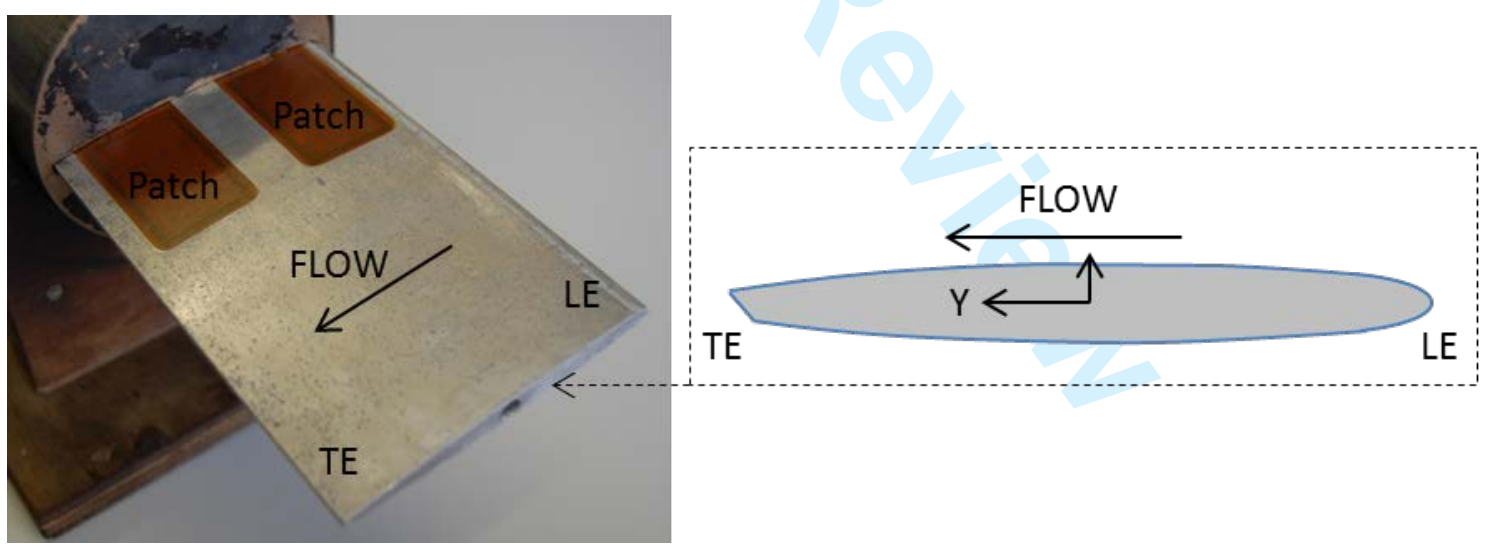

Figure 1- NACA0009 in a cantilever configuration with its subjection system (left) and cross section from leading edge, LE, to trailing edge, TE, (right).

To excite the structure, two PZT patches were embedded on the hydrofoil surface as shown in Figure 1 (left) to keep the hydraulic profile and to avoid affecting the flow around the profile. For that, the NACA0009 hydrofoil surface had to be mechanized. Each patch has a length of $61 \mathrm{~mm}$, a width of 35 $\mathrm{mm}$ and a thickness of $0.5 \mathrm{~mm}$. Thanks to the small thickness, no significant effect is expected on the dynamic response of the hydrofoil. 
A Laser-Doppler Vibrometer (LDV) was used to measure the hydrofoil response with the test setup configuration represented in Figure 2 (left). The LDV can measure the velocity of the surface displacement $(\mathrm{mm} / \mathrm{s})$ at a given position through the upper transparent window of the cavitation tunnel made of plexiglass.

\subsection{Testing conditions}

Four different conditions were tested with the same foil and the same PZT patches:

- $\quad$ Tunnel empty of water (Air)

- $\quad$ Tunnel full of still water (Still Water)

- $\quad$ Tunnel with flowing water (Flowing Water)

- Tunnel with flowing water and leading edge, LE, cavitation (Cavitating)

The flow velocity was fixed at approximately $11.8 \mathrm{~m} / \mathrm{s}$ because it was found to be the minimum velocity necessary to obtain a controllable and stable cavity of approximately $50 \%$ of the chord similar to the one shown in Figure 2. The incidence angle was $0^{\circ}$ through all the conditions. The sigma value was changed to retain the flow velocity and obtain the leading edge cavity.

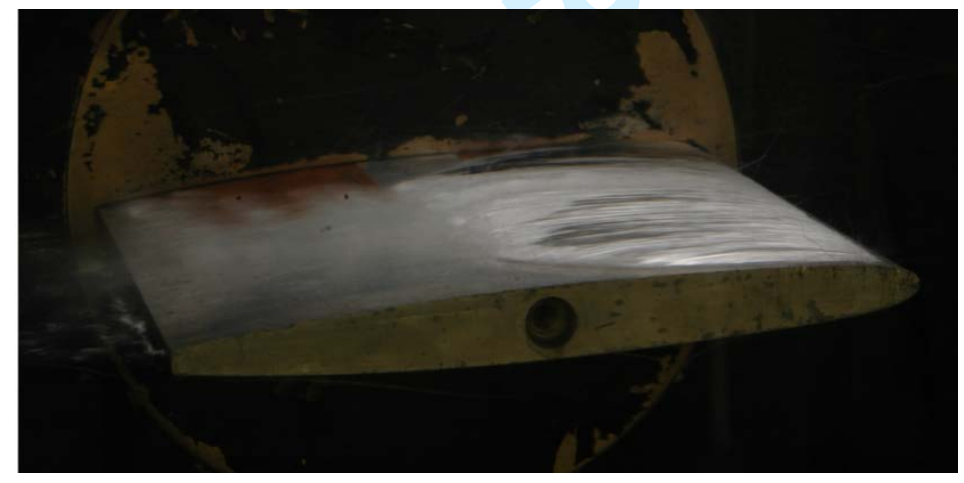

Figure 2. Typical half chord length attached cavity on a truncated NACA0009 hydrofoil homologous to the one used for the current tests under cavitation conditions (flow from right to left).

It has to be mentioned that for the cavitating condition, to avoid the typical interference that bubbles and macrocavities produce on the laser beam, the cavity was attached to the lower side of the hydrofoil while the LDV was measuring on the upper surface as represented on Figure 3 (left). In addition, to be able to produce a cavity sheet at zero incidence angle, the presence of a strip of roughness at the hydrofoil's LE 
was required. The strip consisted of a $2 \mathrm{~mm}$ band of sand glued next to the stagnation point with a thickness of approximately $200 \mu \mathrm{m}$.

\subsection{Procedure}

The test procedure was analogous for each operating condition. The first step was to identify the first three natural frequencies of the hydrofoil which correspond to the first bending mode $\left(f_{1}\right)$, first torsion mode $\left(f_{2}\right)$ and second bending mode $\left(f_{3}\right)$ by means of modal analysis. With the PZT patches, different chirp signals were generated to sweep wide frequency bands. The observation of the measured hydrofoil response allowed to identify each natural frequency when amplified by the effect of the resonance. During the natural frequency identification, one of the patches worked as an exciter and the other as a sensor. The interested reader can find a more detailed experimental procedure in De La Torre et al. (2013).

Once the natural frequencies were obtained, the profile was excited at each particular frequency and the response of the hydrofoil was recorded for each of the 26 different measurement points along the upper surface as shown in Figure 3 (right). These points were distributed in spanwise and chordwise directions along the hydrofoil surface visually accessible. The distance between points is approximately 0.025 and $0.02 \mathrm{~m}$ in spanwise and chordwise directions, respectively, except for the last column of points $(1,7,11$, 17 and 21) which is located at only $0.018 \mathrm{~m}$ from the previous one. Moreover, the first column of points (6, 16 and 26) is located approximately $0.02 \mathrm{~m}$ from the clamped foil tip. These positions were marked by means of reflective tape because it improves the intensity of the reflected laser beam. 

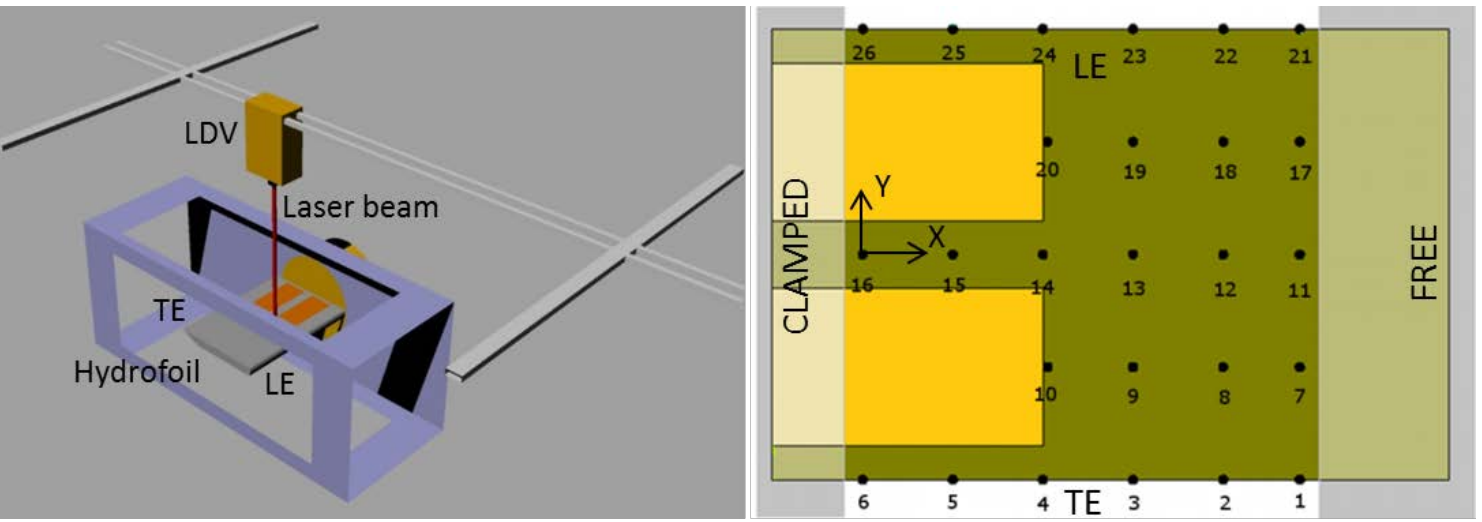

Figure 3. Test setup configuration with the hydrofoil located within the tunnel test section (left) and measurement points on the surface of the foil with grey zones indicating the non-visually accessible parts (right).

The tests were repeated for each mode of vibration and flow condition. The LDV was adjusted sequentially to the all the points and, for each of them, the foil response to a 60 seconds sine signal was recorded. Depending on the noise level of the measured response, only the patch at the LE was used as the exciter or both patches were used. Each mode shape was characterized by calculation of the vibration amplification factors (gains) under resonance conditions. The amplitude gain for each position was obtained by means of a Cross Power Spectrum between the excitation signal and the LDV response signal. The phase was calculated with respect to the patch but a reference accelerometer located outside the test section on the subjection system was used for verification in case of doubts.

The acquired data were post processed by means of ME’ScopeVES ${ }^{\circledR}$ in the time and frequency domains. As a result, the relative amplitude of each point vibration and the phase shift relative to a reference signal were computed. This software allowed us to display spatially defined data such as mode shapes. Therefore, we were able to animate and observe the actual motion of the structure under study. For mode shape visualization, the actual shape of the profile was simplified to a $0.15 \times 0.1 \mathrm{~m}$ cantilevered plate with 35 positions (see Figures 4 to 6 ) including the exact position of the 26 measured points shown in Figure 3 (right). Because the software permitted the movement of non-measured points of the structure to be interpolated, the approximate total plate motion was obtained. It is important to mention that the point numbering does not correspond to the acquisition points represented in Figure 3 (right), it is only an internal reference system for the software to represent the geometry. 


\section{Results}

The natural frequency values of the three modes of vibration are summarized in Table 1 for all the tested scenarios. The corresponding hydrofoil mode shapes are presented in Figures 4, 5 and 6 where each mode shape is shown separately with a $3 \mathrm{D}$ graph. The visualization of the mode shapes under different conditions permits their comparison. In these plots, the yellow color denotes the maximum relative amplitude of vibration and the dark blue color denotes the minimum one. In this geometric simplification the TE is the left border. The corresponding numerical values (gain and phase) are summarized in Tables A.1, A.2 and A.3 in the appendix.

\begin{tabular}{|c|c|c|c|}
\hline & $\boldsymbol{f}_{\mathbf{1}}$ & $\boldsymbol{f}_{\mathbf{2}}$ & $\boldsymbol{f}_{\mathbf{3}}$ \\
\hline Air & $270 \mathrm{~Hz}$ & $1021 \mathrm{~Hz}$ & $1657 \mathrm{~Hz}$ \\
\hline Still Water & $125 \mathrm{~Hz}$ & $625 \mathrm{~Hz}$ & $875 \mathrm{~Hz}$ \\
\hline Flowing Water & $131 \mathrm{~Hz}$ & $643 \mathrm{~Hz}$ & $895 \mathrm{~Hz}$ \\
\hline Cavitating & $134 \mathrm{~Hz}$ & $670 \mathrm{~Hz}$ & $961 \mathrm{~Hz}$ \\
\hline
\end{tabular}

Table 1. Natural frequency values for all the studied cases. 


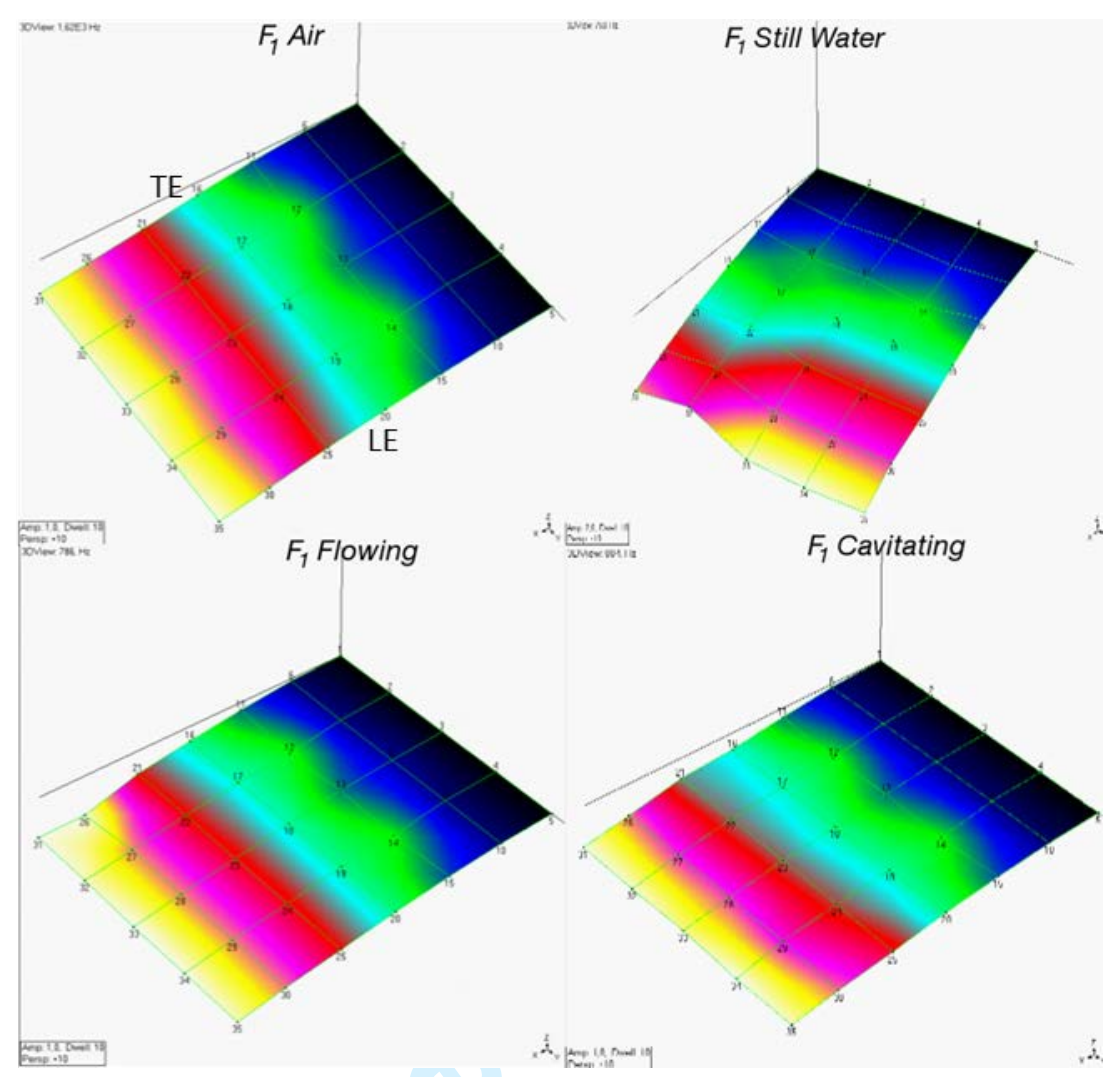

Figure 4. Mode shape visualizations for $f_{1}$ under different fluid conditions.

For the first bending mode, $f_{1}$, there are no significant changes of the mode of vibration in terms of shape. However, important differences are found when comparing the vibration amplification factors of the surface points. The largest gains are found with air at all the points. Then, when the foil is submerged in still water, a $50 \%$ average reduction of gains is observed due to the increase of damping by the water loading relative to air. When the fluid is set in motion, a further reduction in gains is observed with an average of approximately $60 \%$ relative to air. This phenomenon is consistent with the experimental results obtained by Reese (2010) who stated that the total system damping increases again with the flow velocity due to the dynamic changes in the fluid flow. Finally, with the presence of partial cavitation, the average reduction is approximately $65 \%$. These reductions are not so evident for higher order modes. 


\section{Page 9 of 23}

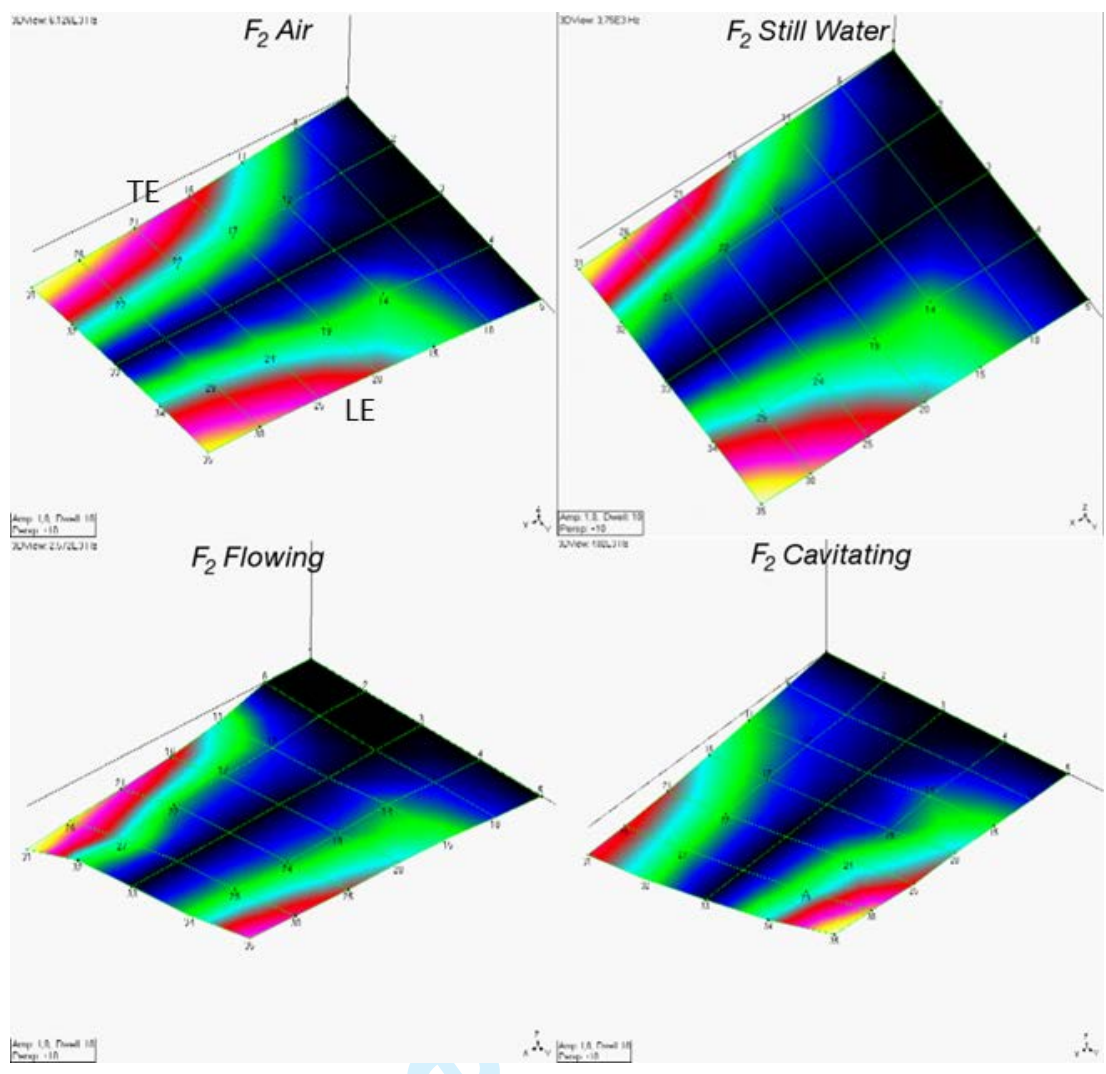

Figure 5. Mode shape visualizations for $f_{2}$ under different fluid conditions.
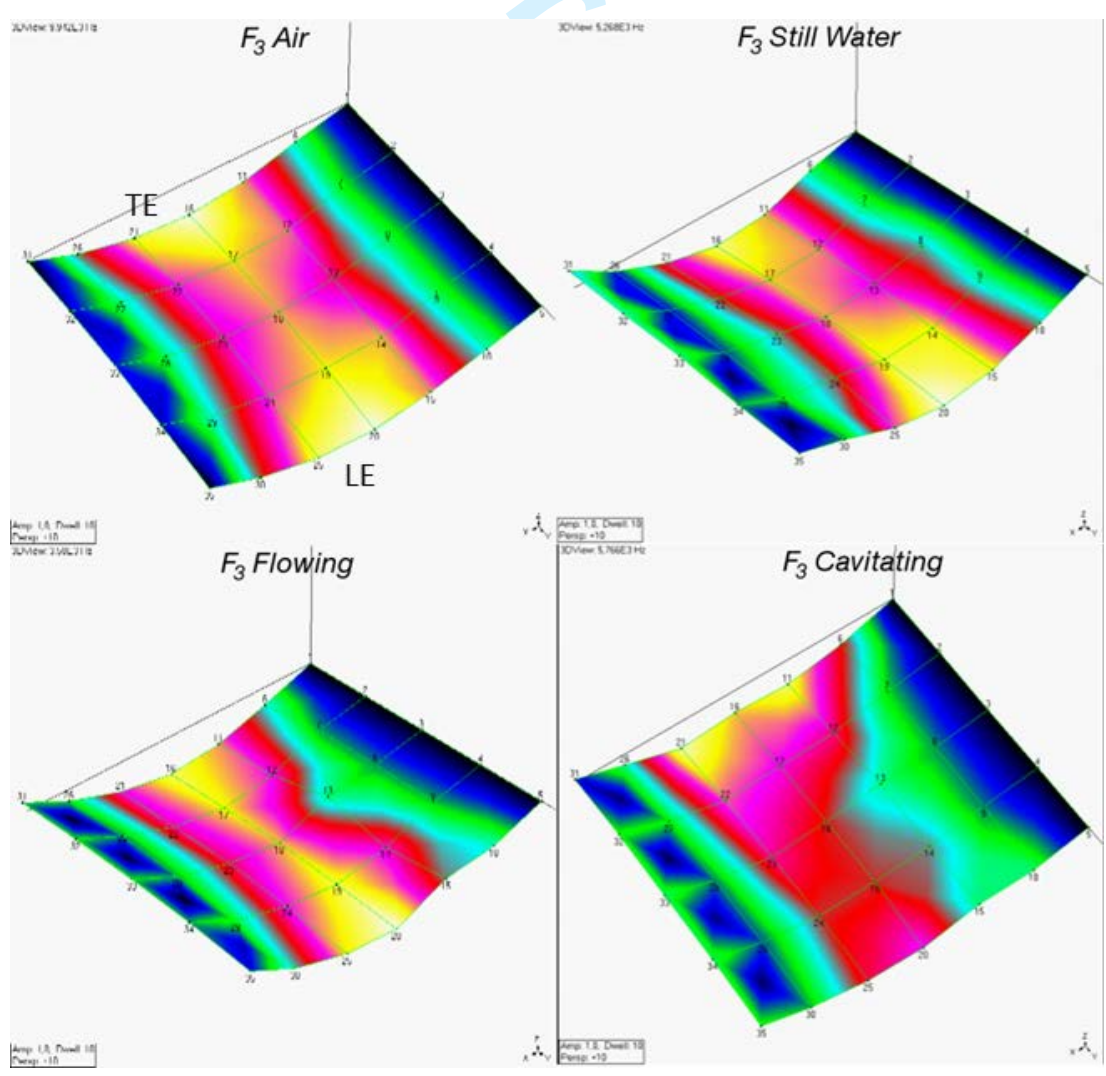

Figure 6. Mode shape visualizations for $f_{3}$ under different fluid conditions. 
The first torsion, $f_{2}$, and second bending, $f_{3}$, modes exhibit some additional differences among the tested conditions because they present a nodal line (NL) on the hydrofoil's surface. In particular, the $f_{3}$ mode shape under a cavitating flow resembles a slightly coupled mode when animated. In particular, it seems that a bending-torsion mode starts to appear. In fact, it does not appear as clean as the movements under the other conditions and its NL location is very difficult to identify in this case.

To better appreciate such mode shape alterations, the authors have compared the normalized gains relative to their maximum value for each flow condition on several specific points from Figure 3 (right). Moreover, a curve fit has been done to interpolate the gain values for the foil positions in spanwise direction between any two measurements with a method widely used in image correlation (Maude, A., 1971). This method generates a continuous function $G$ (and continuous first derivative) at all points and computes a weighted average following equation (1) and choosing $W$ as indicated by equation (2). For the values in chordwise direction, a simple linear fit has been considered. And finally, the theoretical mode shapes have been calculated considering the hydrofoil as a cantilever beam and deriving the equations of motion of each mode according to the Euler-Bernoulli theory.

$$
\begin{gathered}
G=W G_{n}+(1-W) G_{n+1} \\
W=1-3\left(\frac{\left(x-x_{n}\right)}{\left(x_{n+1}-x_{n}\right)}\right)^{2}+2\left(\frac{\left(x-x_{n}\right)}{\left(x_{n+1}-x_{n}\right)}\right)^{3}
\end{gathered}
$$

In Figures 7 and 8 , the $f_{3}$ and $f_{2}$ normalized gains, their curve fits and the theoretical values have been plotted, respectively, for a set of points located close to the TE in the spanwise direction (points 1-2-3-45-6). This particular location has been chosen because the thickness of the hydrofoil in this location is the lowest. For this particular reason, the results are expected to be closer to the theoretical approach based in the thin beam theory. 
Figure 7. Second bending mode, $f_{3}$, normalized gains relative to the maximum of measuring points 1-2-3-

4-5-6 aligned in the spanwise direction, their curve fits and the theoretical values for the different test conditions.

As observed in Figure 7 from the curve fits, the NL in air is located at about $77.6 \%$ of the hydrofoil's span which is very close to the beam theory prediction at $77.4 \%$. When submerged in still water, the NL moves backwards to the clamped section at $69.8 \%$. This result is qualitatively consistent with the findings of Lindholm et al. (1965) and Fu et al. (1987) who, unfortunately, could not quantify the NL movement. Additionally, this phenomenon seems to be enhanced by the lateral gap located between the hydrofoil's tip and the plexiglass wall of the tunnel test section which is filled with fluid. This gap increases the added mass effect significantly as concluded by De La Torre et al. (2014). Finally, under flowing water conditions, the NL moves back to the tip of the hydrofoil up to about $72.6 \%$ which seems in good agreement with the behavior of the natural frequency that also increases (Table 1). Finally, for cavitating flow the NL keeps the same position than with flowing water. Because the differences in NL position are greater than $2 \%$ of the maximum expected error, we might conclude that they are caused by the flow condition. 
Figure 8. First torsion mode, $f_{2}$, normalized gains relative to the maximum of measuring points 1-2-3-4-5-

6 aligned in the spanwise direction, their curve fits and the theoretical values for the different test conditions.

In Figure 8, it is clearly observed that the foil deformation measured in air agrees quite precisely with the theoretical prediction. In the case of still water, analogous results are obtained if the local measurement at position $X=0.02 \mathrm{~m}$ is discarded. Then, for flowing water and cavitating conditions all the relative gains are reduced and the shapes differ from the previous ones especially when cavitation is present.

In Figure 9, the $f_{2}$ normalized gains, their curve fits and the theoretical values have been plotted for a set of points in the chordwise direction (points 1-7-11-17-21) that complement the analysis of this torsion mode since it is the visible location where more significant deformations are expected. 
Figure 9. First torsion mode, $f_{2}$, normalized gains relative to the maximum of measuring points 1-7-11-

17-21 aligned in the chordwise direction, their curve fits and the theoretical values for the different test conditions.

In Figure 9, the NL for the air condition is located at about $51.5 \%$ of the hydrofoil's chord. In this case, it is believed that the asymmetry of the profile moves the NL from the expected $50 \%$ position towards the LE. When submerged in still water, the NL moves to about $47.3 \%$ from the TE. Under flowing water condition, the NL moves back up to about $53.4 \%$. And finally, with cavitation it is located at $44.5 \%$ that is the minimum distance from the TE. Again, the positional differences are slightly higher than the $2 \%$ maximum error threshold.

In summary, submergence in still water produces a measurable displacement of the NL for both $f_{2}$ and $f_{3}$ relative to air condition. Then, the NL displacement occurs in the opposite direction under flowing water relative to still water condition. 


\section{Discussion}

In particular, the observed changes of mode shapes with different flow conditions seem to be related with the changes of added mass. The added mass is essentially a function of the geometry of the surface, the position relative to the boundary conditions, the amplitude and direction of the vibration and a Reynoldslike coefficient, as proposed by Blevins (1979). Nevertheless, this formulation does not explain the effect on the mode shapes.

If we assume a finite element model and hence a matrix formulation for a body vibrating in fluid, its dynamic behavior can be represented by equation (3):

$$
\left(\mathbf{M}+\mathbf{A}_{\text {fluid }}\right) \ddot{\mathbf{x}}+\left(\mathbf{C}+\mathbf{B}_{\text {fluid }}\right) \dot{\mathbf{x}}+\left(\mathbf{K}+\mathbf{D}_{\text {fluid }}\right) x=\mathbf{F} \text { (3) }
$$

where $\mathbf{M}, \mathbf{C}$ and $\mathbf{K}$ stand for mass, damping and stiffness matrices, respectively; $\mathbf{A}_{\text {fluid }}, \mathbf{B}_{\text {fluid }}$ and $\mathbf{D}_{\text {fluid }}$ stand for added mass, added damping and added stiffness matrices, respectively; and $\mathbf{F}$ is the fluid loading matrix. As stated above, a change in $\mathbf{M}, \mathbf{C}$ or $\mathbf{K}$ would not affect the eigenfunctions (mode shapes) of the modal coordinate system. To obtain solutions for different systems, the added matrices and the excitation forces should be different in nature because they are not only influenced by the boundary conditions of the structure.

Regarding the added terms due to the fluid loading, the obtained results might be explained as follows:

- The change between air and still water conditions is mainly due to the new $\mathbf{A}_{\text {fluid }}$ term. When submerged in a still dense fluid, the added mass effect is much more important than the added damping, and the added stiffness is almost negligible.

- When setting the fluid in motion, an increase in the hydrodynamic damping might take place so that the new system's solution is influenced by the $\mathbf{B}_{\text {fluid }}$ matrix.

- When cavitation appears, the pressure equilibrium between the upper and lower sides of the profile is not maintained, and as a result, a net torque appears along the spanwise axis. This torque could increase the $\mathbf{D}_{\text {fluid }}$ term. Moreover, the $\mathbf{A}_{\text {fluid }}$ matrix has also changed due to the presence of a large vapor cavity within the fluid domain around the hydrofoil. In this case, the final mode shape configurations come from a new weighted combination of the $\mathbf{A}_{\text {fluid }}$, $\mathbf{B}_{\text {fluid }}$ and $\mathbf{D}_{\text {fluid }}$ matrices. 


$$
V_{n}^{\prime}(x)=\text { transient term }+\frac{1}{m_{n} \omega_{n}} \int_{0}^{L} Q_{n}(\tau) \sin \left[\omega_{n}(t-\tau)\right] d \tau
$$

$$
Q_{n}(t)=\int_{0}^{l} f(x, t) \cdot V_{n}(x) d x
$$

If we focus on the permanent term in equation (5) it is clear that, in general, it will be different to the one presented by equation (4). This is equivalent to say that its mode shapes and natural frequencies will be different because the excitation force greatly influences the system solution. Therefore, for different excitations we can expect different solutions as observed from the current experiments.

Each forced vibration case creates differences in the loads applied to the cantilevered foil. Even if there is no net flow, the water viscosity might play a role when the structure moves relatively to it. Moreover, small scale flows might be generated at the profile's edges producing measurable forces over the submerged structure. Finally, the presence of attached cavitation alters the whole pressure distribution around the hydrofoil.

As a conclusion, it is evident that for each flow condition the theory predicts differences in the mode shapes as stated experimentally in the current work. 


\section{Conclusions}

The three first modes of vibration of a cantilevered NACA0009 hydrofoil have been identified, measured, visualized and compared under different conditions including air, still water, flowing water and cavitation. All the modes measured in air condition agree reasonably with the predicted ones by the thin beam theory of a cantilever beam.

The first bending mode, $f_{1}$, presents a reduction in the magnitude of the surface deformations relative to the air condition of approximately $50 \%, 60 \%$ or $65 \%$ when the hydrofoil is submerged in still water, flowing water or cavitating conditions, respectively.

The presence of a nodal line, NL, for the torsion, $f_{2}$, and the second bending, $f_{3}$, modes permits to measure differences in the mode shapes related to a change in its position. Both modes present measurable displacements of their NL with maximum values of about $8 \pm 2 \%$ depending on the flow condition. The NL movements from air to still water and from still water to flowing water conditions occur in opposite directions.

A leading edge cavity of approximately $50 \%$ of the chord causes a relevant change of the $f_{3}$ mode shape that resembles a bending-torsion coupled mode.

\section{References}

[1] Avellan, F., Henry, P., Ryhming, I.L.,1987. A new high speed cavitation tunnel. ASME Winter Annual Meeting, Boston, vol. 57, pp. 49-60.

[2] Blake, W.K., 1972. On the Damping of Transverse Motion of Free-Free Beams in Dense, Stagnant Fluids. Journal of Shock and Vibration Bulletin 42, no. Part 4:41-55.

[3] Blake, W.K., Maga, L.J., 1975. On the flow-excited vibrations of cantilever struts in water. I. Flowinduced damping and vibration. Journal of the Acoustical Society of America 57, no. 3: 610-625.

[4] Blake, W.K., Maga, L.J., 1973. Vibratory Dynamics of Flow-Excited Struts in Water. Naval Ship Research and Development Center. Report 4087.

[5] Blevins, R.D.,1979. Formulas for natural frequency and mode shape. Krieger, Malabar. 
[6] De La Torre. O., 2013. Influence of cavitation on the dynamic response of hydrofoils. PhD Thesis, UPC, Barcelona.

[7] De La Torre, O., Escaler, X., Egusquiza, E., Farhat, M., 2013. Experimental investigation of added mass effects on a hydrofoil under cavitation conditions. Journal of Fluids and Structures, vol 39, 173-187. [8] De La Torre, O., Escaler, X., Egusquiza, E., Farhat, M., 2014. Numerical and experimental study of a nearby solid boundary and partial submergence effects on hydrofoil added mass. Computers and Fluids, vol 91, 1-9.

[9] Fu, Y., Price, W.G., 1987.Interactions between a partially or totally immersed vibrating cantilever plate and the surrounding fluid. Journal of Sound and Vibration, vol 118, issue 3.

[10] Kwak, M.K., Yang, D.-H., 2013. Free vibration analysis of cantilever plate partially submerged into a fluid. Journal of Fluids and Structures, vol 40, 25-41.

[11] Lindholm, U.S., Kana, D.D., Chu, W-C., Abramson, H.N., 1965. Elastic vibration characteristics of cantilever plates in water. J Ship Res; 9:11-22.

[12] Maude, A., 1971. Interpolation-mainly for graph plotters. The computer Journal, volume 16 num 1.

[13] Rajaomazava III, T.E., Benaouicha, M., Astolfi, J.-A., 2013. Structure dynamics analysis in inhomogeneous density flows. Proceedings of the ASME 2013 Pressure Vessels and Piping Division Conference, Paris, France.

[14] Reese, M.C., 2010. Vibration and damping of hydrofoils in uniform flow, Master Thesis, Pennsylvania State University.

[15] Rodriguez, C.G., Egusquiza, E., Escaler, X., Liang, Q.W., Avellan, F., 2006. Experimental investigation of added mass effects on a Francis turbine runner in still water. Journal of Fluids and Structures, 22:699-712.

[16] Sader, J.E., 1998. Frequency response of cantilever beams immersed in viscous fluids with applications to the atomic force microscope. Journal of Applied Physics, vol 84, 1.

\section{Appendix}

\begin{tabular}{c|cccc|cccc}
\hline Point & \multicolumn{3}{|c|}{ Gain [-] } & \multicolumn{4}{c}{ Phase [0] } \\
\cline { 2 - 4 } number & Air & Still & Flowing & Cavitating & Air & Still & Flowing & Cavitating \\
& & Water & Water & & & Water & Water & \\
\cline { 2 - 3 } & & & & &
\end{tabular}




\begin{tabular}{|c|c|c|c|c|c|c|c|c|}
\hline $\mathbf{1}$ & 0.96 & 0.81 & 1.00 & 0.97 & 22.5 & 146.6 & 67.2 & 120.6 \\
\hline 2 & 0.79 & 0.62 & 0.99 & 0.79 & 21.9 & 146.7 & 67.8 & 114.0 \\
\hline 3 & 0.57 & 0.44 & 0.57 & 0.53 & 22.3 & 146.8 & 65.9 & 126.8 \\
\hline 4 & 0.36 & 0.29 & 0.38 & 0.39 & 22.8 & 146.9 & 65.0 & 116.4 \\
\hline 5 & 0.18 & 0.16 & 0.21 & 0.21 & 24.2 & 147.5 & 64.0 & 121.1 \\
\hline 6 & 0.06 & 0.06 & 0.07 & 0.07 & 30.2 & 149.0 & 60.9 & 114.9 \\
\hline 7 & 0.97 & 0.70 & 0.97 & 0.94 & 22.2 & 146.4 & 67.8 & 125.7 \\
\hline 8 & 0.78 & 0.55 & 0.80 & 0.74 & 21.8 & 146.5 & 67.7 & 121.1 \\
\hline 9 & 0.58 & 0.40 & 0.58 & 0.49 & 22.0 & 146.6 & 67.6 & 124.4 \\
\hline 10 & 0.39 & 0.26 & 0.40 & 0.39 & 22.4 & 146.7 & 67.2 & 127.6 \\
\hline 11 & 1.00 & 0.99 & 1.00 & 0.97 & 22.3 & 146.5 & 68.5 & 127.7 \\
\hline 12 & 0.80 & 0.76 & 0.79 & 0.73 & 21.7 & 146.5 & 68.8 & 115.1 \\
\hline 13 & 0.59 & 0.56 & 0.59 & 0.50 & 22.3 & 146.6 & 68.7 & 118.9 \\
\hline 14 & 0.39 & 0.37 & 0.39 & 0.38 & 22.7 & 146.8 & 69.7 & 125.6 \\
\hline 15 & 0.22 & 0.21 & 0.22 & 0.22 & 23.7 & 147.3 & 72.3 & 124.9 \\
\hline 16 & 0.09 & 0.09 & 0.09 & 0.07 & 26.3 & 148.4 & 77.4 & 132.0 \\
\hline 17 & 0.96 & 1.00 & 1.00 & 1.00 & 20.3 & 146.4 & 68.8 & 120.2 \\
\hline 18 & 0.77 & 0.75 & 0.79 & 0.68 & 19.4 & 146.4 & 69.1 & 119.0 \\
\hline 19 & 0.58 & 0.58 & 0.59 & 0.53 & 20.6 & 146.5 & 69.6 & 119.9 \\
\hline 20 & 0.37 & 0.36 & 0.37 & 0.38 & 21.0 & 146.7 & 71.7 & 117.0 \\
\hline 21 & 1.00 & 0.96 & 0.98 & 0.99 & 19.6 & 146.3 & 69.7 & 120.0 \\
\hline 22 & 0.80 & 0.75 & 0.78 & 0.75 & 20.0 & 146.3 & 69.5 & 121.9 \\
\hline 23 & 0.54 & 0.57 & 0.65 & 0.60 & 21.1 & 146.3 & 76.0 & 124.8 \\
\hline 24 & 0.35 & 0.35 & 0.42 & 0.37 & 21.7 & 146.3 & 76.0 & 121.3 \\
\hline 25 & 0.19 & 0.16 & 0.20 & 0.19 & 20.5 & 146.3 & 76.3 & 121.3 \\
\hline 26 & 0.06 & 0.07 & 0.08 & 0.06 & 22.3 & 146.3 & 76.4 & 130.1 \\
\hline
\end{tabular}

Table A.1. First bending mode shape results: Relative displacement magnitude and phase. 


\begin{tabular}{|c|c|c|c|c|c|c|c|c|}
\hline \multirow{2}{*}{$\begin{array}{c}\text { Point } \\
\text { number }\end{array}$} & \multicolumn{4}{|c|}{ Gain [-] } & \multicolumn{4}{|c|}{ Phase [o] } \\
\hline & $\overline{\text { Air }}$ & $\begin{array}{c}\text { Still } \\
\text { Water }\end{array}$ & $\begin{array}{l}\text { Flowing } \\
\text { Water }\end{array}$ & Cavitating & $\overline{\text { Air }}$ & $\begin{array}{c}\text { Still } \\
\text { Water }\end{array}$ & $\begin{array}{l}\text { Flowing } \\
\text { Water }\end{array}$ & Cavitating \\
\hline 1 & 1.00 & 0.96 & 1.00 & 0.70 & -46.3 & -34.4 & 100.8 & 121.7 \\
\hline 2 & 0.91 & 0.86 & 0.88 & 0.62 & -46.8 & -36.5 & 102.0 & 108.5 \\
\hline 3 & 0.79 & 0.71 & 0.76 & 0.54 & -47.1 & -37.9 & 103.1 & 120.1 \\
\hline 4 & 0.63 & 0.50 & 0.62 & 0.41 & -46.8 & -41.6 & 104.0 & 124.6 \\
\hline 5 & 0.43 & 0.31 & 0.39 & 0.29 & -46.5 & -46.3 & 104.5 & 128.5 \\
\hline 6 & 0.20 & 0.14 & 0.00 & 0.15 & -45.8 & -47.6 & -23.7 & 137.2 \\
\hline 7 & 0.50 & 0.33 & 0.34 & 0.35 & -47.5 & -41.5 & 147.1 & 97.1 \\
\hline 8 & 0.46 & 0.26 & 0.41 & 0.33 & -47.4 & -44.8 & 122.9 & 97.4 \\
\hline 9 & 0.41 & 0.22 & 0.26 & 0.28 & -47.1 & -47.2 & 152.6 & 105.7 \\
\hline 10 & 0.33 & 0.17 & 0.22 & 0.23 & -46.9 & -50.0 & 155.2 & 105.1 \\
\hline 11 & 0.02 & 0.02 & 0.04 & 0.06 & -59.2 & 156.5 & 64.0 & -8.2 \\
\hline 12 & 0.03 & 0.01 & 0.03 & 0.06 & -54.8 & 171.8 & 65.7 & 9.6 \\
\hline 13 & 0.03 & 0.02 & 0.03 & 0.08 & -53.4 & -178.7 & 62.3 & 25.9 \\
\hline 14 & 0.03 & 0.02 & 0.03 & 0.10 & -57.7 & -129.9 & 50.1 & 35.0 \\
\hline 15 & 0.02 & 0.03 & 0.05 & 0.11 & -67.2 & -155.3 & 58.6 & 47.5 \\
\hline 16 & 0.01 & 0.03 & 0.00 & 0.08 & -67.9 & -166.4 & -22.9 & 43.5 \\
\hline 17 & 0.47 & 0.53 & 0.31 & 0.45 & 133.4 & 141.6 & -22.6 & -66.9 \\
\hline 18 & 0.43 & 0.43 & 0.29 & 0.40 & 134.1 & 141.5 & -23.3 & -67.9 \\
\hline 19 & 0.36 & 0.35 & 0.24 & 0.32 & 134.3 & 142.1 & -21.8 & -61.8 \\
\hline 20 & 0.28 & 0.28 & 0.22 & 0.24 & 135.1 & 145.7 & -18.2 & -32.4 \\
\hline 21 & 0.91 & 1.00 & 0.78 & 1.00 & 134.1 & 145.3 & -27.9 & -79.0 \\
\hline 22 & 0.82 & 0.82 & 0.67 & 0.85 & 134.0 & 143.9 & -47.7 & -82.2 \\
\hline 23 & 0.71 & 0.66 & 0.55 & 0.60 & 133.9 & 142.3 & -35.5 & -72.5 \\
\hline 24 & 0.55 & 0.51 & 0.46 & 0.48 & 133.9 & 141.5 & -41.1 & -71.3 \\
\hline 25 & 0.37 & 0.36 & 0.35 & 0.32 & 133.9 & 141.1 & -38.7 & -72.7 \\
\hline
\end{tabular}




\begin{tabular}{lllllllll}
\hline 26 & 0.18 & 0.17 & 0.16 & 0.14 & 133.4 & 140.4 & -38.7 & -66.2 \\
\hline
\end{tabular}

\begin{tabular}{|c|c|c|c|c|c|c|c|c|}
\hline Point & & & in [-] & & & $\overline{\mathbf{P h}}$ & e [o] & \\
\hline number & Air & $\begin{array}{c}\text { Still } \\
\text { Water }\end{array}$ & $\begin{array}{c}\text { Flowing } \\
\text { Water }\end{array}$ & $\begin{array}{c}\text { Cavitati } \\
\text { ng }\end{array}$ & Air & $\begin{array}{c}\text { Still } \\
\text { Water }\end{array}$ & $\begin{array}{c}\text { Flowing } \\
\text { Water }\end{array}$ & $\begin{array}{c}\text { Cavitati } \\
\text { ng }\end{array}$ \\
\hline $\mathbf{1}$ & 0.03 & 0.48 & 0.26 & 0.35 & 53.5 & 65.5 & 18.2 & 65.6 \\
\hline 2 & 0.51 & 0.16 & 0.28 & 0.41 & 120.7 & -103.3 & -136.2 & -41.5 \\
\hline 3 & 0.88 & 0.66 & 0.71 & 1.00 & 124.7 & -109.4 & -146.3 & -57.3 \\
\hline 4 & 1.00 & 0.94 & 0.92 & 0.85 & 125.2 & -112.6 & -148.0 & -51.6 \\
\hline 5 & 0.80 & 0.82 & 0.44 & 0.92 & 126.9 & -113.3 & -147.7 & -64.3 \\
\hline 6 & 0.39 & 0.36 & 0.44 & 0.57 & 130.7 & -108.7 & -146.2 & -58.5 \\
\hline 7 & 0.10 & 0.41 & 0.29 & 0.32 & -42.7 & 69.4 & 26.1 & 99.6 \\
\hline 8 & 0.37 & 0.14 & 0.22 & 0.29 & 121.7 & -112.6 & -139.3 & -57.9 \\
\hline 9 & 0.73 & 0.57 & 0.67 & 0.76 & 123.4 & -113.2 & -148.4 & -65.1 \\
\hline 10 & 0.84 & 0.83 & 0.86 & 0.71 & 123.9 & -115.0 & -148.7 & -66.1 \\
\hline 11 & 0.15 & 0.39 & 0.28 & 0.35 & -48.5 & 73.1 & 31.9 & 122.8 \\
\hline 12 & 0.35 & 0.18 & 0.24 & 0.25 & 121.2 & -119.4 & -153.0 & -92.2 \\
\hline 13 & 0.68 & 0.49 & 0.63 & 0.69 & 122.3 & -115.3 & -151.1 & -80.6 \\
\hline 14 & 0.80 & 0.81 & 0.82 & 0.64 & 121.4 & -119.9 & -151.8 & -90.9 \\
\hline 15 & 0.65 & 0.71 & 0.37 & 0.57 & 119.4 & -124.6 & -148.2 & -103.8 \\
\hline 16 & 0.34 & 0.48 & 0.22 & 0.35 & 117.6 & -126.3 & -151.8 & -114.1 \\
\hline 17 & 0.11 & 0.25 & 0.25 & 0.34 & -52.1 & 75.9 & 37.2 & 136.3 \\
\hline 18 & 0.42 & 0.28 & 0.32 & 0.30 & 123.2 & -117.7 & -156.4 & -108.8 \\
\hline 19 & 0.75 & 0.54 & 0.72 & 0.60 & 122.8 & -114.3 & -151.8 & -91.3 \\
\hline 20 & 0.85 & 0.89 & 0.90 & 0.64 & 120.4 & -121.8 & -153.1 & -99.1 \\
\hline 21 & 0.01 & 0.15 & 0.14 & 0.33 & -103.9 & 76.8 & 52.7 & 149.3 \\
\hline 22 & 0.53 & 0.22 & 0.46 & 0.40 & 125.5 & -124.9 & -154.9 & -111.1 \\
\hline
\end{tabular}




\section{List of figure captions}

Figure 1- NACA0009 in a cantilever configuration with its subjection system (left) and cross section from leading edge, LE, to trailing edge, TE, (right).

Figure 2. Typical half chord length attached cavity on a truncated NACA0009 hydrofoil homologous to the one used for the current tests under cavitation conditions (flow from right to left).

Figure 3. Test setup configuration with the hydrofoil located within the tunnel test section (left) and measurement points on the surface of the foil with grey zones indicating the non-visually accessible parts (right).

Figure 4. Mode shape visualizations for $f_{1}$ under different fluid conditions.

Figure 5. Mode shape visualizations for $f_{2}$ under different fluid conditions.

Figure 6. Mode shape visualizations for $f_{3}$ under different fluid conditions.

Figure 7. Second bending mode, $f_{3}$, normalized gains relative to the maximum of measuring points 1-2-34-5-6 aligned in the spanwise direction, their curve fits and the theoretical values for the different test conditions.

Figure 8. First torsion mode, $f_{2}$, normalized gains relative to the maximum of measuring points 1-2-3-4-56 aligned in the spanwise direction, their curve fits and the theoretical values for the different test conditions. 
Figure 9. First torsion mode, $f_{2}$, normalized gains relative to the maximum of measuring points 1-7-11-

17-21 aligned in the chordwise direction, their curve fits and the theoretical values for the different test conditions.

\section{Notation}

$f_{1} \quad$ First bending mode

$f_{2} \quad$ First torsion mode

$f_{3} \quad$ Second bending mode

$f(x, t) \quad$ Loading function

I Cantilever beam length

$t \quad$ Time

$\mathrm{x} \quad$ Position or Point value

$x_{n} \quad$ Interval boundary value

Afluid $_{\text {Fluid added mass matrix }}$

B $_{\text {fluid }} \quad$ Fluid added damping matrix

C Structure damping matrix

$\mathrm{C}_{\text {fluid }} \quad$ Fluid added stiffness matrix

F $\quad$ Fluid loading matrix

$G \quad$ Weighted average function

$G_{n} \quad$ Second order polynomial 
1

2

3

4

5

6

7

8

9

10

11

12

13

14

15

16

17

18

19

20

21

22

23

24

25

26

27

28

29

30

31

32

33

34

35

36

37

38

39

40

41

42

43

44

45

46

47

48

49

50

51

52

53

54

55

56

57

58

59

60

K Structure stiffness matrix

LDV Laser-doppler vibrometer

LE Leading edge

M Structure mass matrix

ND Nodal line

PZT Piezo electric ceramic

TE Trailing edge

$V(x) \quad$ Mode shape function for free vibration

$V^{\prime}(x) \quad$ Mode shape function for forced vibration

W Interpolation polynomial function

$X \quad$ Distance from origin of reference system

$\beta_{n} \quad$ Factor of mode $\mathrm{n}$

$Q_{n}(t) \quad$ Modal force coefficient

$\omega_{n} \quad$ Natural frequency of mode $n$

$\tau \quad$ Impulse time 